\title{
Survivin overexpression in head and neck squamous cell carcinomas as a new therapeutic target (Review)
}

\author{
M.A. FRASSANITO ${ }^{1 *}$, I. SALTARELLA ${ }^{2 *}$, A. VINELLA ${ }^{1}$, L. LO MUZIO ${ }^{3}$, \\ G. PANNONE ${ }^{3}$, R. FUMARULO ${ }^{1}$, A. VACCA ${ }^{2}$ and M.A. MARIGGIÒ ${ }^{1}$ \\ ${ }^{1}$ Department of Biomedical Sciences and Human Oncology, Unit of General Pathology, and \\ ${ }^{2}$ Department of Biomedical Sciences and Human Oncology, Unit of Internal Medicine and Clinical Oncology, \\ University of Bari Aldo Moro, I-70124 Bari; ${ }^{3}$ Department of Clinical and Experimental Medicine, \\ University of Foggia, I-70121 Foggia, Italy
}

Received October 30, 2018; Accepted March 13, 2019

DOI: $10.3892 /$ or.2019.7082

\begin{abstract}
Head and neck squamous cell carcinoma (HNSCC) is the sixth most commonly diagnosed cancer worldwide. It has poor clinical outcome due to intrinsic or acquired drug resistance. Deregulation of both apoptosis and autophagy contributes to chemotherapy resistance and disease progression. A new member of the inhibitors of apoptosis protein (IAP) family, namely survivin, is selectively overexpressed in tumors, including HNSCC, but not in normal tissues. Thus, it is considered a tumor biomarker. Here, we reviewed survivin expression and function in tumor progression focusing on its nodal role in the regulation of cell apoptosis and autophagy. Based on literature data, survivin targeting may be envisaged as a novel therapeutic strategy.
\end{abstract}

\section{Contents}

1. Introduction

2. Survivin

3. Survivin and apoptosis

4. Survivin and autophagy

5. Survivin in head and neck squamous cell carcinoma

6. Survivin as a therapeutic target

Correspondence to: Professor Maria Addolorata Mariggiò, Department of Biomedical Sciences and Human Oncology, Unit of General Pathology, University of Bari Aldo Moro, Piazza G. Cesare 11, I-70124 Bari, Italy

E-mail: mariaaddolorata.mariggio@uniba.it

${ }^{*}$ Contributed equally

Key words: survivin, head and neck squamous cell carcinoma, apoptosis, autophagy

\section{Introduction}

Head and neck squamous cell carcinoma (HNSCC) represents one of the most commonly diagnosed cancer worldwide (1). It develops in the squamous mucosa of the upper aerodigestive tract i.e. lip, tongue, nasopharynx, oropharynx and larynx. Accordingly, HNSCC is a heterogeneous group that includes oral squamous cell carcinoma (OSCC) and oropharyngeal squamous cell carcinoma (OPSCC) as the most common histotypes (2). Tumorigenesis and progression of HNSCC starts from a precancerous lesion to a malignant primary tumor to a metastatic tumor. This sequence implies that tumor cells acquire a more aggressive phenotype over time. Recent genomic and functional studies highlight the role of several tumor-suppressor pathways, including p53, Rb/INK4/ARF, PI3K/AKT/mTor and Notch, in the molecular pathogenesis of HNSCC (3). Tobacco use, alcohol consumption and infection of human papilloma virus (HPV) are the most important risk factors $(4,5)$. Based on HPV infection, HNSCC is subgrouped into HPV-positive and HPV-negative forms that differ in regards to prognosis. HPV-negative HNSCC cases have poor prognosis and their outcome has not improved in the last few years (5). Conventional HNSCC therapy depends on tumor site and stage, and includes surgery, chemotherapy, radiotherapy and radio-chemotherapy. However, due to intrinsic or acquired drug resistance, both overall survival and prognosis still remain poor (6). Chemotherapy resistance is related to genomic complexity, intratumoral genetic heterogeneity and epigenetic modifications, i.e. DNA methylation, histone covalent modifications, chromatin remodelling and miRNAs, which contribute to the activation/inactivation of oncogenes/tumor-suppressor genes involved in key cellular functional pathways, namely cell proliferation, apoptosis, and autophagy $(2,3)$.

Apoptosis is an evolutionarily conserved process responsible for the removal of damaged/non-functioning cells. Tumor progression and drug resistance implicate suppression of apoptosis by several mechanisms including an altered balance between pro-survival, i.e survivin, and pro-death proteins (7-10).

Autophagy is a mechanism involved in the adaptation of tumor cells to drug treatment (11-13). It maintains 
intracellular homeostasis by lysosomal degradation and recycling of unnecessary or damaged cell components (14). Preclinical studies demonstrated that treatment with several chemotherapeutic drugs, i.e. vorinostat, cyclophosphamide, imatinib and bortezomib, activates autophagy in tumor cells as a prosurvival mechanism $(6,11,12)$. Thus, specific drugs targeting apoptosis or autophagy pathways are currently under investigations (10-12).

Here, we describe survivin expression and function in regards to tumor progression focusing on its key role in cell cycle, apoptosis and autophagy.

\section{Survivin}

In 1997, Ambrosini et al (9) identified survivin, also known as baculoviral inhibitor of apoptosis repeat (BIR)-containing 5 (BIRC5), as a new member of the inhibitors of apoptosis protein (IAP) family (15). It is widely overexpressed in most malignancies including HNSCC (16). It is a multifunctional protein involved in the regulation of several cell processes, such as apoptosis and mitosis, through the coordination of the spindle checkpoint system and of the chromosome passenger protein complex (CPC), microtubule dynamics and cell response to stress (15). All of these functions are related to its structure (17).

Survivin is the smallest member of the IAP family that is composed of 142 amino acids with a single N-terminal $\mathrm{Zn}^{2+}$-binding BIR domain and a C-terminal with $\alpha$-helix motif (15). Both domains are essential for its functions; the former binds the target proteins involved in the regulation of apoptosis and mitosis, the latter contains a microtubule binding site that allows interactions between survivin and the cytoskeleton $(15,16)$. Analysis of crystal structure of human survivin demonstrates its bow tie-shaped dimer containing two unusual C-terminal $\alpha$-helical extensions interacting with several proteins (18).

The survivin gene locus (BIRC5) is located on chromosome $17 q 25$ and encodes for multiple alternative splice variants: Survivin full length, survivin $2 \alpha$ (this has a new open reading frame and a new stop codon encoding for a truncated 74 amino acids protein), survivin $2 \mathrm{~B}$ (this contains only a part of intron 2), survivin 3B (this has additional 3B exon with a stop codon), and survivin $\triangle E x 3$ (this lacks 118 nucleotides of exon 3$)(15,19,20)$. Alternative survivin splice variants show different heterodimerization ability and different subcellular localization and functions that account for survivin multiple functional roles in normal and tumor cells (21). In particular, survivin $2 \alpha$ restrains the anti-apoptotic activity of survivin, survivin 2B displays no anti-apoptotic activity and antagonizes the anti-apoptotic isoforms, and the function of survivin $3 \mathrm{~B}$ remains unknown (22).

Fortugno et al (23) identified distinct survivin subcellular pools, including a predominant cytosolic fraction and a smaller nuclear pool that localizes to kinetochores of metaphase chromosomes. The cytosolic pool is associated with interphase microtubules, centrosomes, spindle poles and mitotic spindle microtubules at metaphase and anaphase. In synchronized HeLa cell cultures, cytosolic survivin is phosphorylated by p34cdc2 on Thr34, and increases during mitosis. By contrast, nuclear survivin starts to accumulate in S-phase, it is neither complexed with p34cdc2 nor phosphorylated on Thr34.
Analysis on the SWISS-PROT and YPD databases predicted a preferential cytoplasmic localization of survivin and survivin 2B, and a preferential nuclear localization of survivin $\Delta \mathrm{Ex} 3(21)$. In tumor cells, survivin is also located in mitochondria associated to heat shock protein 90 (Hsp90); as a response to apoptotic stimuli it is released into the cytosol and suppresses apoptosis (24).

Survivin expression is tightly regulated through multiple cell signaling pathways at transcriptional and post-transcriptional levels leading to its overexpression during tumorigenesis and drug resistance (25). The survivin promoter region lacks the typical TATA or CCAAT box, and harbors binding sites for a range of regulatory proteins, including specificity protein 1 (Sp1) and p53. The observations that: i) Survivin overexpression parallels increased levels of Sp1, ii) Sp1 mutations reduces the expression of BIRC5 gene, and iii) Sp1 inhibition by mithramycin or RNA interference decreases the survivin promoter activity, point to a central role of $\mathrm{Sp} 1$ in the regulation of survivin gene transcription (25). The p53 protein is a transcription factor that induces apoptosis by regulating the expression of several apoptotic genes. In particular, the wild-type p53 binds specific elements of the survivin promoter and represses survivin expression $(15,25,26)$.

Insulin-like growth factor 1 (IGF-1) promotes cell proliferation and survivin expression via activation of the PI3K/AKT/mTOR pathway (27). Several lines of evidence show that the STAT3 pathway regulates survivin gene expression. Constitutive activation of STAT3 in primary effusion lymphoma, gastric cancer and breast cancer cells correlates to survivin overexpression, disease progression and tumor cell survival $(28,29)$. Inhibition of STAT3 with antisense oligonucleotides reduces survivin expression and sensitizes breast cancer cells to chemotherapy proving that survivin is a direct STAT3-target gene (30). Moreover, survivin is a downstream target of the YAP/COX-2/PGE2 pathway. A genome microarray analysis showed that the overexpression of the transcriptional coactivator YAP triggers COX-2 and increases survivin expression sustaining cell survival and proliferation (31).

Post-translational modifications, including phosphorylation and acetylation, regulate the survivin cell functions. Phosphorylation of the amino acid Thr34 in the BIR domain prevents the binding of survivin to caspase-9, inhibits intrinsic apoptosis (see the section below), and increases its cytoprotective effect in tumor cells (Fig. 1) (32). Mitochondrial and cytosolic survivin play a different apoptotic role that depends on the phosphorylation of Ser20. In response to pro-apoptotic stimuli, the mitochondrial dephosphorylated Ser20 survivin is released into the cytosol and prevents caspase activation by complexing with X-linked IAP (XIAP). In contrast, survivin is phosphorylated on Ser20 by polo-like kinase1 (PLK1), a multitasking protein involved in cell mitotic entry, centrosome separation, spindle assembly and chromosome alignment. Phosphorylated Ser20 survivin binds to and activates Aurora B kinase forming the $\mathrm{CPC}$, which plays an important role in cytokinesis (Fig. 1) (25).

\section{Survivin and apoptosis}

Survivin was originally identified as an IAP family member (9) acting as a death suppressor (33-35). Subsequently, Li et al (36) 


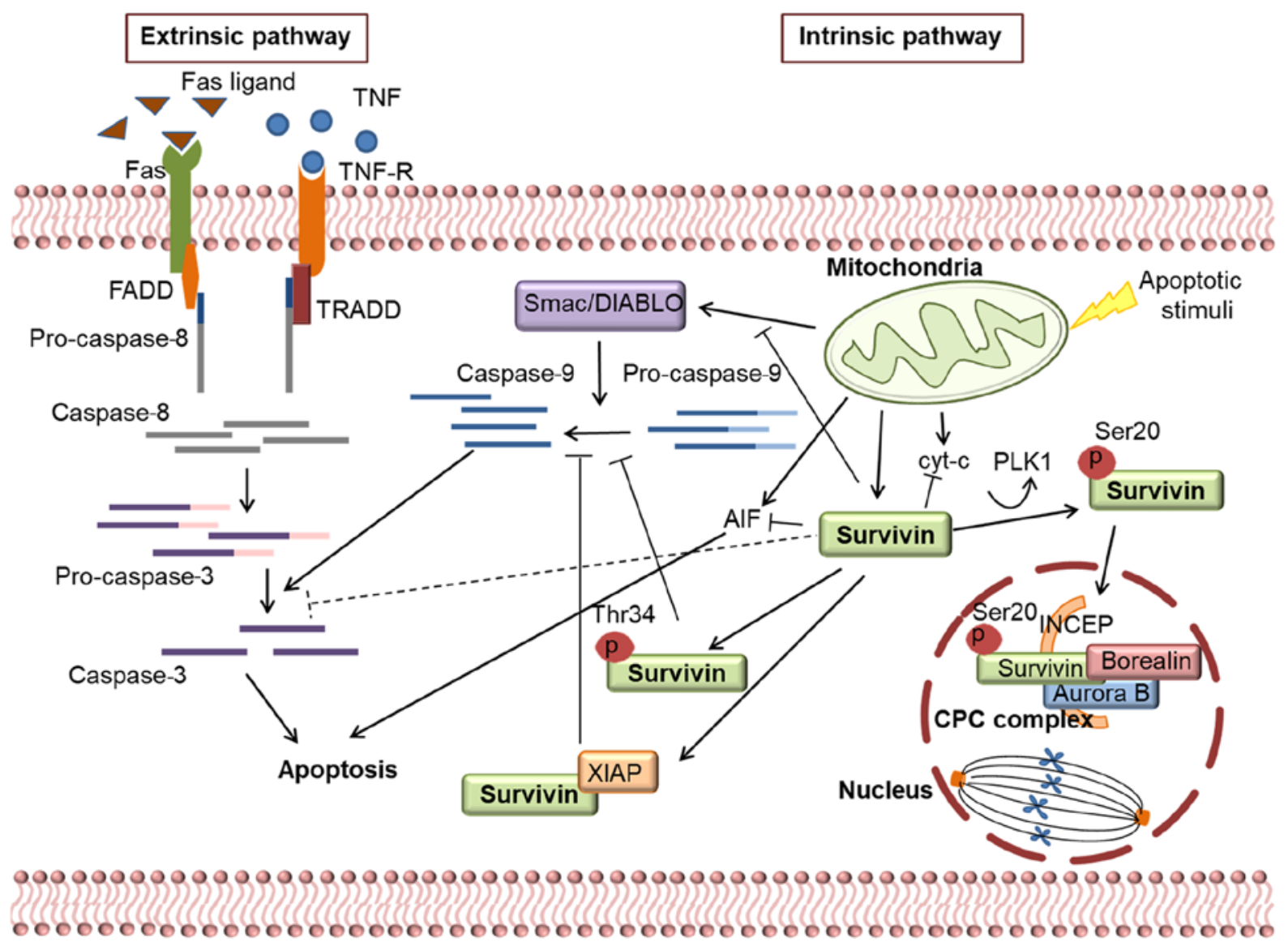

Figure 1. Schematic illustration of survivin involvement in apoptotic and mitotic processes. Cell apoptosis can occur through the extrinsic and the intrinsic pathways. In the former, the binding of Fas ligand or tumor necrosis factor (TNF) to a death receptor (Fas or TNF-R) activates caspase-8. In stress conditions (UV radiation and/or chemotherapy), cells initiates the mitochondrial pathway (intrisinc apoptosis) leading to the release of apoptotic factors, i.e. cytochrome $c$ (cyt c), apoptosis-inducing factor (AIF) and Smac/DIABLO, that in turn cleave pro-caspase-9 into caspase-9. Cytosolic survivin prevents caspase-9 activation, by binding to Smac/DIABLO, and/or to X-linked IAP (XIAP) and/or by its phosphorylation on Thr34, preventing the activation of caspase-3. Survivin affects the caspase-independent apoptosis by inhibiting AIF. Survivin is involved in cell cycle progression and mitosis allowing chromosome alignment, segregation and cytokinesis. After phosphorylation by polo-like kinase1 (PLK1) on Ser20, it binds to and activates Aurora B kinase moving to the nucleus, where it forms the chromosome passenger complex (CPC) with Borealin and inner centromere protein Antigen (INCEP).

demonstrated that survivin acts as an interface between the cell cycle and apoptosis. Indeed, interference with survivin expression or function induces pleiotropic cell cycle and apoptosis defects, i.e. supernumerary centrosomes, aberrant mitotic spindles, and polyploidy. The use of a dominant-negative survivin mutant or antisense survivin complementary DNA disrupts the assembly of survivin, caspase-3 and cyclin-dependent-kinase inhibitor $\mathrm{p} 21^{\text {Waf1/Cip1 }}$ within centrosomes, suggesting that survivin controls apoptosis and is required for normal progression of mitosis (36). Survivin has also been suggested as a nodal protein involved in multiple signaling mechanisms in tumor initiation and progression (26). In mammalian cells, survivin participates in mitosis, apoptosis, and cellular stress response (24).

Survivin is an anti-apoptotic factor. It interacts with many factors that regulate intrinsic and extrinsic apoptotic pathways. It binds to XIAP and prevents XIAP ubiquitination and proteasomal destruction. The survivin/XIAP complex avoids caspase- 9 cleavage and activation, inhibits apoptosis, activates several signaling pathways, and promotes tumor progression (37). The direct interaction of survivin with caspases is controversial. Indeed, some authors have described the interaction of survivin with caspases (38), while others have ruled out the effects of this interaction on their activity (37). This discrepancy may be explained by the ability of survivin to also inhibit caspase-independent apoptosis by interacting with the apoptosis-inducing factor (AIF) (39). Indeed, inhibition of survivin in breast cancer cells results in the nuclear translocation of mitochondrial AIF that causes DNA fragmentation and induces apoptosis with no effect on caspase-3 cleavage (39). Finally, survivin regulates mitochondrial apoptosis by preventing the Smac/DIABLO release from mitochondria (40). Following the apoptotic stimulus, Smac/DIABLO is released into the cytosol where it neutralizes IAPs, including XIAPs, and potentiates apoptosis (41). Song et al (42) demonstrated that a point mutation in the baculoviral IAP repeat motif and a C-terminal deletion mutant (Surv-BIR) of survivin fail to bind to Smac/DIABLO and abrogate its anti-apoptotic effect.

The role of survivin has been also studied in the cellular stress response through its association with various molecular chaperones, including Hsp60 (43) and Hsp90 (44) that increase survivin stability and promote cell survival under cellular stress conditions. 


\section{Survivin and autophagy}

Autophagy is a highly conserved self-degradative process that is essential for maintaining cell homeostasis in both physiological and pathological conditions such as removal of misfolded proteins or damaged organelles and elimination of intracellular pathogens in response to nutrient deprivation or stress conditions $(11,14,45)$. Autophagy plays a dual role in tumors: i) It can support cell survival and drug resistance; ii) it can prevent tumor cell transformation inducing a non-apoptotic cell death also known as type II programmed cell death. The cross-regulation of these opposite effects relies on a network of signal transducers of autophagic and apoptotic processes (46). Indeed, a mutual crosstalk between Bcl-2/Beclin 1 (47), Atg5/BCL-xl (48), Atg12/Bcl2 (49), caspase-3/Beclin 1 (50), caspase-8/p62 (51), and caspase-9/Atg7 (52) that are the most important proteins involved in both processes has been demonstrated.

Survivin is involved in the cellular stress response by interfering with autophagy. It interacts with different proteins of the autophagic machinery (53). Niu et al (54) demonstrated that Beclin 1 is able to bind to survivin (Fig. 2). Its knockdown results in survivin downregulation through ubiquitination and proteasome degradation, and enhances TRAIL-induced apoptosis in human glioma cells. Roca et al (55) demonstrated that the chemokine (C-C motif) ligand 2 (CCL2), an inflammatory cytokine with multiple effects on prostate cancer (56), induces survivin overexpression via the PI3K/Akt/mTOR pathway. Treatment of the CCL2-exposed prostate cancer cell line PC3 with PI3K or AKT or mTOR inhibitors reduced the CCL2-mediated upregulation of survivin and induced cell death (55). Indeed, mTOR, the most important negative regulator of autophagy, increases the mRNA stability and translation of survivin (Fig. 2) (55). Furthermore, survivin interacts with the microtubule-associated protein 1 light chain 3 (LC3), interfering with the formation of autophagosomes and preventing LC3-I cleavage into LC3-II. The targeting of survivin by YM155, the first-in-class survivin inhibitor (57), was found to increase the conversion of LC3-II and to promote autophagy-related cell death in breast cancer cells (58).

\section{Survivin in head and neck squamous cell carcinoma}

Due to its selective expression in tumors, including HNSCCs, but not in normal tissues, survivin has been proposed as a tumor biomarker $(15,16)$. Immunohistochemical analysis of survivin expression in OSCC, pre-neoplastic lesions, and oral leukoplakia shows a significant overexpression in approximately $80 \%$ of OSCCs and $50 \%$ of premalignant lesions, suggesting that survivin may be involved in the early stages of tumor progression $(59,60)$. Survivin is also considered a predictor factor of disease progression; $94 \%$ of oral precancerous lesions showing survivin positivity evolve into full-blown OSCCs (61). Survivin expression correlates with more aggressive and poorly differentiated tumor phenotype, lymph node metastasis, poor prognosis and reduced patient survival rate $(59,61-68)$, indicating that survivin could be a prognostic factor for tumor progression and patient outcome. Recently, Xie et al (69) performed a meta-analysis including 15 studies in order to compare the different clinicopathological features or survival rates with survivin expression in 1,040 OSCC patients (69). In this report, authors defined a significant association among survivin overexpression, poor prognosis, lymph node metastasis and clinical stage without a significant correlation with the clinicopathological values, i.e. tumor differentiation grade, depth of invasion, age and sex. The absence of the clinicopathological significance of survivin may be explained by the presence of splice variants and/or by the different subcellular localization and function of survivin (69).

Engels et al (70) examined the localization and prognostic value of nuclear and cytoplasmic survivin in the pre-therapeutic biopsies from 71 OSCC patients. Cytoplasmic survivin was found to be associated with poor overall survival and disease outcome. The authors suggested that the balance between cytoplasmic and nuclear survivin in tumor cells is a critical factor for the survivin cytoprotective activity. Recently, Liu et al (71) examined survivin expression in 90 paired primary OSCC and adjacent normal tissue by immunohistochemistry. Although total survivin levels were higher in OSCC than in normal oral tissue, nuclear survivin was associated with the TNM classification of malignant tumors and tumor grade. Furthermore, in vitro experiments using OSCC cell lines demonstrated that cytoplasmic survivin mediates protection against chemo- and radio-therapy-induced apoptosis. Troiano et al (72) revealed that cytoplasmic expression of survivin is associated with poor overall survival in OSCC patients, while its nuclear expression correlates with a higher proliferation rate. Kaplan-Meier (univariate) and Cox regression (multivariate) analysis showed that only the cytoplasmic expression of survivin was an independent prognostic factor of overall survival. The authors performed an integrated analysis of $B I R C 5 /$ survivin expression using both immunohistochemistry and bioinformatics on publicly available databases in order to identify the molecular mechanisms causing survivin overexpression. Bioinformatic analysis revealed a low frequency of survivin gene mutations, and found a correlation of survivin overexpression to the alteration of genes that regulates $B I R C 5$ expression such as $A K T$, BUB, CDKN2A1, FOXM1, KIF23, MYC, PRKACA and STAG2. The most recurring mutation was the homozygous deletion of $C D K N 2 A$ gene encoding for p16(INK4A) and p14(ARF) proteins (72) that govern cell cycle progression. CDKN2A mutations and cytoplasmic survivin immunostaining have been associated with higher risk of melanoma (73).

Epigenetic modifications in the regulation of survivin expression play a role in HNSCC (74). Since the BIRC5 promoter is a GC-rich region, its hypomethylation is an important step in OSCC tumorigenesis $(75,76)$. Tanaka et al (77) analyzed the methylation status of the BIRC5 promoter in OSCCs and oral pre-malignant lesions, and showed that the hypomethylation of this promoter occurs in all tumor tissues.

p53 participates in the survivin upregulation in OSCCs (76). Khan et al (78) reported a positive correlation between $\mathrm{p} 53$ and survivin expression in both HNSCC and premalignant lesions. This evidence suggests that p53 is involved at the early stage in oral cancer development and contributes to survivin overexpression and apoptosis deregulation.

As previously mentioned, the survivin gene locus encodes for multiple alternative splice variants with several heterodimerization possibilities and different functions (19-22). Analysis in 20 HNSCC cell lines at different levels of 


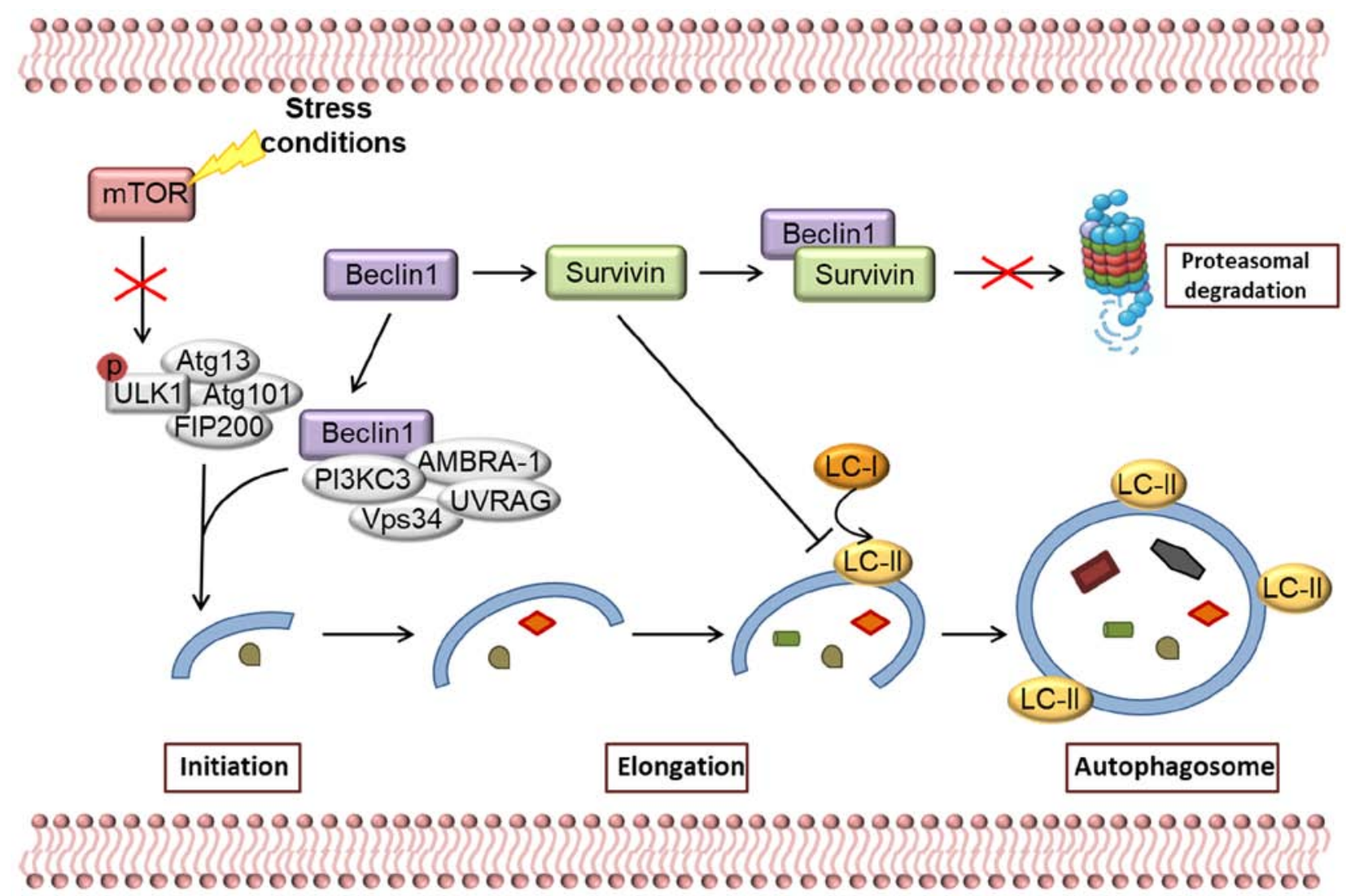

Figure 2. Schematic illustration of the involvement of survivin in the autophagic process. In stress conditions (i.e. nutrient deprivation, hypoxia, oxidative stress, DNA damage), mTOR inhibition triggers autophagy through activation of autophosphorylated ULK1/Atg13/Atg101/FIP200 complex. This complex recruits Beclin-1/PI3KC3/Vps34/AMBRA-1/UVRAG resulting in the first steps of phagophore formation (autophagosome initiation phase). The elongation process requires the cleavage of the microtubule-associated protein light chain 3 (LC3-I) into the autophagic vesicle-associated LC3-II which regulates the fusion of the autophagosome to the lysosome. Beclin 1 binds to survivin suppressing its proteasomal degradation. Survivin acts on the final steps of autophagosome formation by preventing LC3-II cleavage and anchorage.

differentiation showed that these cell lines expressed higher levels of survivin compared to a human neonatal keratinocyte cell line (NHEK) (79-82). Further analysis of the expression of the splice variants (survivin full length, survivin $2 \mathrm{~B}$, survivin $3 \mathrm{~B}$ and survivin $\triangle \mathrm{Ex} 3$ ) by semi-quantitative RT-PCR highlighted that normal NHEK cells expressed low levels of survivin full length and survivin $\triangle \mathrm{Ex} 3$ (unpublished data). By contrast, higher levels of all survivin isoforms including survivin $2 \mathrm{~B}$ and $3 \mathrm{~B}$ were observed in tumor cell lines, suggesting a deregulated ratio between pro-apoptotic and anti-apoptotic survivin splice variants that may affect the pro-survival survivin activity (unpublished data). No correlation between the expression of survivin splice variants and cell differentiation was observed. Indeed, high levels of survivin full length and $\triangle E x 3$ were detected in more differentiated (KM2, OSC30, OSC20 and HSG), in moderately differentiated (Ca9-22, HNT and KM1) and poorly differentiated (KB, HEP2, HSC3) cell lines (unpublished data). De Maria et al (22) analyzed the expression of survivin splice variants, survivin, survivin $2 \mathrm{~B}$, $3 \mathrm{~B}$ and $\triangle \mathrm{Ex} 3$, at the mRNA and protein levels in normal mucosa, oral precancerous lesions and OSCCs. Higher levels of survivin transcripts were observed in OSCCs than these levels in normal tissues. In particular, survivin and survivin $\triangle \mathrm{Ex} 3$ were the most upregulated transcripts followed by survivin $2 \mathrm{~B}$ and $3 \mathrm{~B}$ indicating a trend of association between survivin isoforms and clinicopathological features; survivin 2B was found to be increased in advanced tumors compared to early stage ones; conversely the survivin $\Delta \mathrm{Ex} 3$ decreased during tumor progression and in metastasis (22).

Overall data suggest that the survivin expression may be considered a specific prognostic and therapeutic marker in HNSCCs (83).

\section{Survivin as a therapeutic target}

The observations that survivin is selectively upregulated in almost all types of human malignancies and barely detectable in most terminally differentiated tissues $(84,85)$ and that its overexpression is associated with chemotherapy resistance and tumor recurrence $(15,86)$ suggest that the targeting of survivin may be envisaged as a novel therapeutic strategy $(58,87-89)$.

In the last few years, several authors have investigated the effect of survivin inhibition using different strategies, namely small-molecule inhibitors, antisense nucleotides, antitumor immunotherapy and RNA interference (Table I) (90).

The small-molecule inhibitors directly or indirectly bind survivin and suppress its functions. The most important one is sepantronium bromide YM155. It selectively suppresses survivin expression $(91,92)$ and increases the p53 modulator of apoptosis PUMA levels and caspase-3 activation (92). It induces autophagic and apoptotic cell death of HNSCC cell 


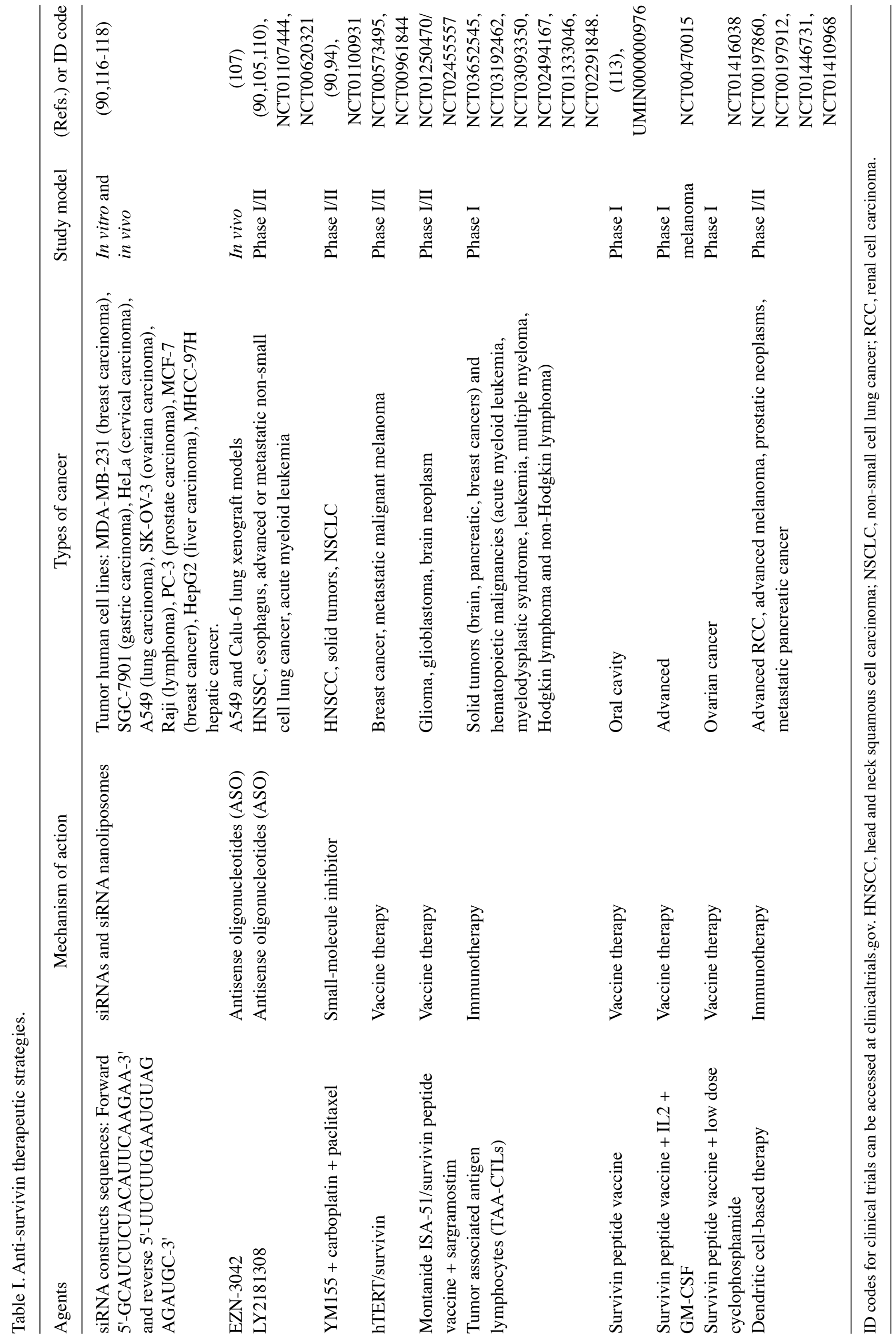


lines by inhibiting the pro-survival Akt/mTOR pathway (93). The therapeutic effect of YM155 was confirmed in vivo using xenograft and transgenic mice models; it delayed HNSCC onset and suppressed tumor growth via apoptosis and autophagy. In phase I/II clinical trials, the effect of YM155 has been investigated in patients with advanced hematological and solid tumors, including HNSCC. YM155 is safe with slight side effects such as microalbuminuria, fever, fatigue, haemoglobin reduction and lymphopenia. However, no positive effects were observed in patients with oesophageal cancer (92,94-97).

Recent studies have documented the role of nonsteroidal anti-inflammatory drugs (NSAIDs) as anticancer drugs through the inhibition of COX2 and the expression of NSAID target genes $(98,99)$. In particular, NSAIDs may affect survivin expression directly by blocking the activity of COX2 (31), and, indirectly, through the inhibition of AKT (100) and/or STAT3 pathways (101) and/or through the degradation of survivin via the ubiquitin proteasome system (102). The NSAID indomethacin was found to reduce survivin and Aurora B kinase and have a proapoptotic effect on human gastric carcinoma cell lines and in mouse gastric mucosa (103). Furthermore, the dual inhibition of YAP and COX2 was found to decrease survivin expression affecting cell apoptosis and invasion in vitro and tumor growth in vivo (31). The NSAID sulindac was demonstrated to downregulate survivin expression in a STAT3-dependent mechanism acting on HNSCC cell lines proliferation and apoptosis in vitro and in vivo (101).

Antisense oligonucleotides (ASO) are single-stranded RNA or DNA sequences of 8-50 nucleotides complementary to a specific RNA strand that suppress the expression of a specific gene. ASO have been developed as a new approach to inhibit survivin expression by binding its human mRNA. Oligonucleotides 4003, LY2181308, SPC3042 and EZN-3042 are survivin ASO that target different regions of mRNA (104-108). ASO are able to reduce cell proliferation by increasing caspase-dependent apoptosis in several tumor cells $(53,105)$. Phase I clinical trials of LY2181308 in patients with advanced cancers, including one patient with OSCC, show great tolerability while no cytotoxic effect and only a promising antitumor activity closely related to survivin inhibition. These clinical trials reveal encouraging data on the pro-apoptotic effect of ASO in combination with other chemotherapeutic agents $(109,110)$.

Antitumor immunotherapy involves the use of vaccines, or immune cells such as natural killer cells, dendritic cells, and cytotoxic T lymphocytes (CTLs) activated in vitro and back transfused to cancer patients $(111,112)$. Several studies (113-115) have identified CTLs specific for survivin epitopes with high cytotoxicity to various tumors, including OSCC. Miyazaki et al (113) initiated a phase I clinical study using survivin $2 \mathrm{~B}$ peptide as vaccine in patients with locally advanced or recurrent OSCC.

Finally, preclinical studies have focused on the inhibition of survivin expression through small interfering RNA (siRNA) (116-118). siRNA targeting survivin in OSCC cell lines was found to reduce cell proliferation, increase apoptosis, and improve the response to chemotherapeutic agents such as cisplatin, 5-fuorouracil and paclitaxel (119-121).

In conclusion, although several studies emphasize targeting survivin as a novel therapeutic strategy in HNSCCs, survivin-based therapy is still a long way from application in clinical trials.

\section{Acknowledgements}

Not applicable.

\section{Funding}

Not applicable.

\section{Availability of data and materials}

The datasets used and analyzed during the present study are available from the corresponding author on reasonable request.

\section{Authors' contributions}

MAF, IS, AVi and MAM conceived, designed the study and wrote the paper. LLM, GP, RF and AVa critically revised the manuscript for important intellectual content and were also involved in the conception of the study. All authors read and approved the manuscript and agree to be accountable for all aspects of the research in ensuring that the accuracy or integrity of any part of the work are appropriately investigated and resolved.

\section{Ethics approval and consent to participate}

Not applicable.

\section{Patient consent for publication}

Not applicable.

\section{Competing interests}

The authors declare that they have no competing interests.

\section{References}

1. Bray F, Ferlay J, Soerjomataram I, Siegel RL, Torre LA and Jemal A: Global cancer statistics 2018: GLOBOCAN estimates of incidence and mortality worldwide for 36 cancers in 185 countries. CA Cancer J Clin 68: 394-424, 2018.

2. Bose P, Brockton NT and Dort JC: Head and neck cancer: From anatomy to biology. Int J Cancer 133: 2013-2023, 2013.

3. Rothenberg SM and Ellisen LW: The molecular pathogenesis of head and neck squamous cell carcinoma. J Clin Invest 122: 1951-1957, 2012.

4. Leemans CR, Braakhuis BJ and Brakenhoff RH: The molecular biology of head and neck cancer. Nat Rev Cancer 11: 9-22, 2011.

5. Fakhry $\mathrm{C}$ and Gillison ML: Clinical implications of human papillomavirus in head and neck cancers. J Clin Oncol 24: 2606-2611, 2006.

6. Wang C, Liu XQ, Hou JS, Wang JN and Huang HZ: Molecular mechanisms of chemoresistance in oral cancer. Chin J Dent Res 19: 25-33, 2016.

7. Brown JM and Attardi LD: The role of apoptosis in cancer development and treatment response. Nat Rev Cancer 5: 231-237, 2005.

8. Mohammad RM, Muqbil I, Lowe L, Yedjou C, Hsu HY, Lin LT, Siegelin MD, Fimognari C, Kumar NB, Dou QP, et al: Broad targeting of resistance to apoptosis in cancer. Semin Cancer Biol 35 (Suppl): S78-S103, 2015.

9. Ambrosini G, Adida C and Altieri DC: A novel anti-apoptosis gene, survivin, expressed in cancer and lymphoma. Nat Med 3: 917-921, 1997. 
10. Mita AC, Mita MM, Nawrocki ST and Giles FJ: Survivin: Key regulator of mitosis and apoptosis and novel target for cancer therapeutics. Clin Cancer Res 14: 5000-5005, 2008.

11. Desantis V, Saltarella I,Lamanuzzi A, Mariggiò MA, Racanelli V, Vacca A and Frassanito MA: Autophagy: A new mechanism of prosurvival and drug resistance in multiple myeloma. Trans Oncol 11: 1350-1357, 2018.

12. Yang ZJ, Chee CE, Huang S and Sinicrope FA: Autophagy modulation for cancer therapy. Cancer Biol Ther 11: 169-176, 2011.

13. Sannigrahi MK, Singh V, Sharma R, Panda NK and Khullar M: Role of autophagy in head and neck cancer and therapeutic resistance. Oral Dis 21: 283-291, 2015.

14. Mizushima N: Autophagy: Process and function. Genes Dev 21: 2861-2873, 2007.

15. Altieri DC: Survivin, versatile modulation of cell division and apoptosis in cancer. Oncogene 22: 8581-8589, 2003.

16. Jaiswal PK, Goel A and Mittal RD: Survivin: A molecular biomarker in cancer. Indian J Med Res 141: 389-397, 2015.

17. Verdecia MA, Huang H, Dutil E, Kaiser DA, Hunter T and Noel JP: Structure of the human anti-apoptotic protein survivin reveals a dimeric arrangement. Nat Struct Biol 7: 602-608, 2000.

18. Chantalat L, Skoufias DA, Kleman JP, Jung B, Dideberg O and Margolis RL: Crystal structure of human survivin reveals a bow tie-shaped dimer with two unusual alpha-helical extensions. Mol Cell 6: 183-189, 2000.

19. Caldas H, Honsey LE and Altura RA: Survivin 2alpha: A novel Survivin splice variant expressed in human malignancies. Mol Cancer 4: 11, 2005.

20. Mahotka C, Wenzel M, Springer E, Gabbert HE and Gerharz CD: Survivin-deltaEx3 and survivin-2B: Two novel splice variants of The apoptosis inhibitor survivin with different antiapoptotic properties. Cancer Res 59: 6097-6102, 1999.

21. Mahotka C, Liebmann J, Wenzel M, Suschek CV, Schmitt M, Gabbert HE and Gerharz CD: Differential subcellular localization of functionally divergent survivin splice variants. Cell Death Differ 9: 1334-1342, 2002

22. De Maria S, Pannone G, Bufo P, Santoro A, Serpico R, Metafora S, Rubini C, Pasquali D, Papagerakis SM, Staibano S, et al: Survivin gene-expression and splicing isoforms in oral squamous cell carcinoma. J Cancer Res Clin Oncol 135: 107-116, 2009.

23. Fortugno P, Wall NR, Giodini A, O'Connor DS, Plescia J, Padgett KM, Tognin S, Marchisio PC and Altieri DC: Survivin exists in immunochemically distinct subcellular pools and is involved in spindle microtubule function. J Cell Sci 115: 575-585, 2002.

24. Altieri DC: New wirings in the survivin networks. Oncogene 27: 6276-6284, 2008.

25. Cheung CH, Huang CC, Tsai FY, Lee JY, Cheng SM, Chang YC, Huang YC, Chen SH and Chang JY: Survivin-biology and potential as a therapeutic target in oncology. Onco Targets Ther 6: 1453-1462, 2013.

26. Altieri DC: Survivin, cancer networks and pathway-directed drug discovery. Nat Rev Cancer 8: 61-70, 2008.

27. Vaira V, Lee CW, Goel HL, Bosari S, Languino LR and Altieri DC: Regulation of survivin expression by IGF-1/mTOR signaling. Oncogene 26: 2678-2684, 2007.

28. Aoki Y, Feldman GM and Tosato G: Inhibition of STAT3 signaling induces apoptosis and decreases survivin expression in primary effusion lymphoma. Blood 101: 1535-1542, 2003.

29. Kanda N, Seno H, Konda Y, Marusawa H, Kanai M, Nakajima T, Kawashima T, Nanakin A, Sawabu T, Uenoyama Y, et al: STAT3 is constitutively activated and supports cell survival in association with survivin expression in gastric cancer cells. Oncogene 23: 4921-4929, 2004.

30. Gritsko T, Williams A, Turkson J, Kaneko S, Bowman T, Huang M, Nam S, Eweis I, Diaz N, Sullivan D, et al: Persistent activation of stat 3 signaling induces survivin gene expression and confers resistance to apoptosis in human breast cancer cells. Clin Cancer Res 12: 11-9, 2006.

31. Li W, Cao Y, Xu J, Wang Y, Li W, Wang Q, Hu Z, Hao Y, Hu L, Sun Y, et al: YAP transcriptionally regulates COX-2 expression and GCCSysm-4 (G-4), a dual YAP/COX-2 inhibitor, overcomes drug resistance in colorectal cancer. J Exp Clin Cancer Res 36: 144, 2017.

32. Barrett RM, Osborne TP and Wheatley SP: Phosphorylation of survivin at threonine 34 inhibits its mitotic function and enhances its cytoprotective activity. Cell Cycle 8: 278-283, 2009.

33. Duckett CS, Nava VE, Gedrich RW, Clem RJ, Van Dongen JL, Gilfillan MC, Shiels H, Hardwick JM and Thompson CB: A conserved family of cellular genes related to the baculovirus iap gene and encoding apoptosis inhibitors. EMBO J 15: 2685-2694, 1996.
34. Deveraux QL, Takahashi R, Salvesen GS and Reed JC: X-linked IAP is a direct inhibitor of cell-death proteases. Nature 388: 300-304, 1997.

35. LaCasse EC, Baird S, Korneluk RG and MacKenzie AE: The inhibitors of apoptosis (IAPs) and their emerging role in cancer. Oncogene 17: 3247-3259, 1998.

36. Li F, Ackermann EJ, Bennett CF, Rothermel AL, Plescia J, Tognin S, Villa A, Marchisio PC and Altieri DC: Pleiotropic cell-division defects and apoptosis induced by interference with survivin function. Nat Cell Biol 1: 461-426, 1999.

37. Altieri DC: Targeting survivin in cancer. Cancer Lett 332: 225-228, 2013.

38. Tamm I, Wang Y, Sausville E, Scudiero DA, Vigna N, Oltersdorf T and Reed JC: IAP-family protein survivin inhibits caspase activity and apoptosis induced by Fas (CD95), Bax, caspases, and anticancer drugs. Cancer Res 58: 5315-5320, 1998.

39. Croci DO, Cogno IS, Vittar NB, Salvatierra E, Trajtenberg F, Podhajcer OL, Osinaga E, Rabinovich GA and Rivarola VA: Silencing survivin gene expression promotes apoptosis of human breast cancer cells through a caspase-independent pathway. J Cell Biochem 105: 381-390, 2008.

40. Ceballos-Cancino G, Espinosa M, Maldonado V and Melendez-Zajgla $\mathrm{J}$ : Regulation of mitochondrial Smac/DIABLO-selective release by survivin. Oncogene 26: 7569-7575, 2007.

41. Du C, Fang M, Li Y, Li L and Wang X: Smac, a mitochondrial protein that promotes cytochrome $c$-dependent caspase activation by eliminating IAP inhibition. Cell 102: 33-42, 2000.

42. Song $\mathrm{Z}$, Yao $X$ and $\mathrm{Wu} \mathrm{M}$ : Direct interaction between survivin and Smac/DIABLO is essential for the anti-apoptotic activity of survivin during taxol-induced apoptosis. J Biol Chem 278: 23130-23140, 2003.

43. Ghosh JC, Dohi T, Kang BH and Altieri DC: Hsp60 regulation of tumor cell apoptosis. J Biol Chem 283: 5188-5194, 2008.

44. Fortugno P, Beltrami E, Plescia J, Fontana J, Pradhan D, Marchisio PC, Sessa WC and Altieri DC: Regulation of survivin function by Hsp90. Proc Natl Acad Sci USA 100: 13791-13796, 2003.

45. Marx J: Autophagy: Is it cancer's friend or foe. Science 312: 1160-1161, 2006.

46. Galluzzi L, Vicencio JM, Kepp O, Tasdemir E, Maiuri MC and Kroemer G: To die or not to die: That is the autophagic question. Curr Mol Med 8: 78-91, 2008.

47. Decuypere JP, Parys JB and Bultynck G: Regulation of the autophagic bcl-2/Beclin 1 interaction. Cells 1: 284-312, 2012.

48. Bhutia SK, Dash R, Das SK, Azab B, Su ZZ, Lee SG, Grant S, Yacoub A, Dent P, Curiel DT, et al: Mechanism of autophagy to apoptosis switch triggered in prostate cancer cells by antitumor cytokine melanoma differentiation-associated gene 7/interleukin-24. Cancer Res 70: 3667-3676, 2010.

49. Haller M, Hock AK, Giampazolias E, Oberst A, Green DR, Debnath J, Ryan KM, Vousden KH and Tait SW: Ubiquitination and proteasomal degradation of ATG12 regulates its proapoptotic activity. Autophagy 10: 2269-2278, 2014.

50. Norman JM, Cohen GM and Bampton ET: The in vitro cleavage of the hAtg proteins by cell death proteases. Autophagy 6: 1042-1056, 2010

51. Wu H, Che X, Zheng Q, Wu A, Pan K, Shao A, Wu Q, Zhang J and Hong Y: Caspases: A molecular switch node in the crosstalk between autophagy and apoptosis. Int J Biol Sci 10: 1072-1083, 2014.

52. Han J, Hou W, Goldstein LA, Stolz DB, Watkins SC and Rabinowich H: A Complex between Atg7 and Caspase-9: A novel mechanism of cross-regulation between autophagy and apoptosis. J Biol Chem 289: 6485-6497, 2014.

53. Coumar MS, Tsai FY, Kanwar JR, Sarvagalla S and Cheung CH: Treat cancers by targeting survivin: Just a dream or future reality. Cancer Treat Rev 39: 802-811, 2013.

54. Niu TK, Cheng Y, Ren X and Yang JM: Interaction of Beclin 1 with survivin regulates sensitivity of human glioma cells to TRAIL-induced apoptosis. FEBS Lett 584: 3519-3524, 2010.

55. Roca H, Varsos ZS, Mizutani K and Pienta KJ: CCL2, survivin and autophagy: New links with implications in human cancer. Autophagy 4: 969-971, 2008.

56. Loberg RD, Day LL, Harwood J, Ying C, St John LN, Giles R, Neeley CK and Pienta KJ: CCL2 is a potent regulator of prostate cancer cell migration and proliferation. Neoplasia 8: 578-586, 2006. 
57. Minematsu T, Iwai M, Sugimoto K, Shirai N, Nakahara T, Usui T and Kamimura H: Carrier-mediated uptake of 1-(2-methoxyeth yl)-2-methyl-4,9-dioxo-3-(pyrazin-2-ylmethyl)-4,9-dihydro- $1 H$ naphtho[2,3- $d$ ]imidazolium bromide (YM155 monobromide), a novel small-molecule survivin suppressant, into human solid tumor and lymphoma cells. Drug Metab Dispos 37: 619-628, 2009.

58. Cheng SM, Chang YC, Liu CY, Lee JY, Chan HH, Kuo CW, Lin KY, Tsai SL, Chen SH, Li CF, et al: YM155 down-regulates survivin and XIAP, modulates autophagy and induces autophagy-dependent DNA damage in breast cancer cells. $\mathrm{Br}$ J Pharmacol 172: 214-234, 2015.

59. Khan Z, Khan AA, Yadav H, Prasad GBKS and Bisen PS Survivin, a molecular target for therapeutic interventions in squamous cell carcinoma. Cell Mol Biol Lett 22: 8, 2017.

60. Rong L, Hongyan Guo H and Liu K: The role of survivin in oral squamous cell carcinoma. Biom Res 29: 780-783, 2018.

61. Lo Muzio L, Pannone G, Leonardi R, Staibano S, Mignogna MD De Rosa G, Kudo Y, Takata T and Altieri DC: Survivin, a potential early predictor of tumor progression in the oral mucosa J Dent Res 82: 923-928, 2003.

62. Lo Muzio L, Pannone G, Staibano S, Mignogna MD, Rubini C, Mariggiò MA, Procaccini M, Ferrari F, De Rosa G and Altieri DC: Survivin expression in oral squamous cell carcinoma. Br J Cancer 89: 2244-2248, 2003.

63. Lo Muzio L, Farina A, Rubini C, Pezzetti F, Stabellini G, Laino G Santarelli A, Pannone G, Bufo P, de Lillo A and Carinci F: Survivin as prognostic factor in squamous cell carcinoma of the oral cavity. Cancer Lett 225: 27-33, 2005.

64. Lo Muzio L, Staibano S, Pannone G, Mignogna MD Mariggiò A, Salvatore G, Chieffi $P$, Tramontano D, De Rosa G and Altieri DC: Expression of the apoptosis inhibitor survivin in aggressive squamous cell carcinoma. Exp Mol Pathol 70 : 249-254, 2001

65. Su L, Wang Y, Xiao M, Lin Y and Yu L: Up-regulation of survivin in oral squamous cell carcinoma correlates with poor prognosis and chemoresistance. Oral Surg Oral Med Oral Pathol Oral Radiol Endod 110: 484-491, 2010.

66. Kim MJ, Lim KY, Kim JW, Nam IW, Lee JH and Myoung H: Stage and mRNA expression of survivin in lymph node as prognostic indicators in patients with oral squamous cell carcinoma. Cancer Lett 224: 253-261, 2005.

67. Zhang M, Li J, Wang L, Tian Z, Zhang P, Xu Q, Zhang C, Wei $\mathrm{F}$ and Chen W: Prognostic significance of p21, p27 and survivin protein expression in patients with oral squamous cell carcinoma. Oncol Lett 6: 381-386, 2013.

68. Münscher A, Prochnow S, Gulati A, Sauter G, Lörincz B, Blessmann M, Hanken H, Böttcher A and Clauditz TS: Survivin expression in head and neck squamous cell carcinomas is frequent and correlates with clinical parameters and treatment outcomes. Clin Oral Investig 23: 361-367, 2019.

69. Xie S, Xu H, Shan X, Liu B, Wang K and CaiZ: Clinicopathological and prognostic significance of survivin expression in patients with oral squamous cell carcinoma: Evidence from a meta-analysis. PLoS One 10: e0116517, 2015.

70. Engels K, Knauer SK, Metzler D, Simf C, Struschka O, Bier C, Mann W, Kovács AF and Stauber RH: Dynamic intracellular survivin in oral squamous cell carcinoma: Underlying molecular mechanism and potential as an early prognostic marker. J Pathol 211: 532-540, 2007.

71. Liu S, Shi L, Yang X, Ye D, Wang T, Dong C, Guo W, Liao Y, Song H, Xu D, et al: Nuclear survivin promoted by acetylation is associated with the aggressive phenotype of oral squamous cell carcinoma. Cell Cycle 16: 894-902, 2017.

72. Troiano G, Guida A, Aquino G, Botti G, Losito NS, Papagerakis S, Pedicillo MC, Ionna F, Longo F, Cantile M, et al: Integrative histologic and bioinformatics analysis of BIRC5/Survivin expression in oral squamous cell carcinoma. Int J Mol Sci 19: pii: E2664, 2018.

73. Aguilera P, Malvehy J, Carrera C, Palou J, Puig-Butillé JA Alòs L, Badenas C and Puig S: Clinical and histopathological characteristics between familial and sporadic melanoma in Barcelona, Spain. J Clin Exp Dermatol Res 5: 231, 2014.

74. Lyu H, Huang J, He Z and Liu B: Epigenetic mechanism of survivin dysregulation in human cancer. Sci China Life Sci 61: 808-814, 2018

75. Chen YK, Hsue SS and Lin LM: Survivin expression is regulated by an epigenetic mechanism for DMBA-induced hamster buccal-pouch squamous-cell carcinomas. Arch Oral Biol 50: 593-598, 2005
76. Hsue SS, Wang WC, Chen YK and Lin LM: Expression of inhibitors of apoptosis family protein in 7,12-dimethylbenz[a] anthracene-induced hamster buccal-pouch squamous-cel carcinogenesis is associated with mutant p53 accumulation and epigenetic changes. Int J Exp Pathol 89: 309-320, 2008.

77. Tanaka C, Uzawa K, Shibahara T, Yokoe H, Noma H and Tanzawa H: Expression of an inhibitor of apoptosis, survivin, in oral carcinogenesis. J Dent Res 82: 607-611, 2003.

78. Khan Z, Tiwari RP, Mulherkar R, Sah NK, Prasad GB, Shrivastava BR and Bisen PS: Detection of survivin and p53 in human oral cancer: Correlation with clinicopathologic findings. Head Neck 31: 1039-1048, 2009.

79. Ikuta M, Podyma KA, Maruyama K, Enomoto S and Yanagishita M: Expression of heparanase in oral cancer cell lines and oral cancer tissues. Oral Oncol 37: 177-184, 2001.

80. Michi Y, Morita I, Amagasa T and Murota S: Human oral squamous cell carcinoma cell lines promote angiogenesis via expression of vascular endothelial growth factor and upregulation of KDR/flk-1 expression in endothelial cells. Oral Oncol 36: $81-88,2000$

81. Gioanni J, Fischel JL, Lambert JC, Demard F, Mazeau C, Zanghellini E, Ettore F, Formento P, Chauvel P, Lalanne CM and Courdi A: Two new human tumor cell lines derived from squamous cell carcinomas of the tongue: Establishment, characterization and response to cytotoxic treatment. Eur J Cancer Clin Oncol 24: 1445-1455, 1988.

82. de Maria S, Lo Muzio L, Braca A, Rega P, Cassano A, Vinella A, Fumarulo R, Serpico R, Farina E, Metafora V, et al: Survivin promoter-31G/C polymorphism in oral cancer cell lines. Oncol Lett 2: 935-939, 2011.

83. Chou J, Lin YC, Kim J, You L, Xu Z, He B and Jablons DM: Nasopharyngeal carcinoma-review of the molecular mechanisms of tumorigenesis. Head Neck 30: 946-963, 2008.

84. Altieri DC: Survivin-The inconvenient IAP. Semin Cell Dev Biol 39: 91-96, 2015.

85. Altieri DC: Survivin and IAP proteins in cell-death mechanisms. Biochem J 430: 199-205, 2010.

86. Chen X, Duan N, Zhang C and Zhang W: Survivin and tumorigenesis: Molecular mechanisms and therapeutic strategies. J Cancer 7: 314-323, 2016.

87. Kanwar JR, Kamalapuram SK and Kanwar RK: Targeting survivin in cancer: The cell-signalling perspective. Drug Discov Today 16: 485-494, 2011.

88. Wang X, Beitler JJ, Huang W, Chen G, Qian G, Magliocca K, Patel MR, Chen AY, Zhang J, Nannapaneni S, et al: Honokiol Radiosensitizes squamous cell carcinoma of the head and neck by downregulation of survivin. Clin Cancer Res 24: 858-869, 2018.

89. Hu J, Pan J, Luo Z and Tao Z: Downregulation of survivin by shRNA inhibits invasion and enhances the radiosensitivity of laryngeal squamous cell carcinoma. Cell Biochem Biophys 72: 251-257, 2015.

90. Santarelli A, Mascitti M, Lo Russo L, Sartini D, Troiano G, Emanuelli M and Lo Muzio L: Survivin-based treatment strategies for squamous cell carcinoma. Int J Mol Sci 19: pii: E971, 2018.

91. Nakahara T, Kita A, Yamanaka K, Mori M, Amino N, Takeuchi M, Tominaga F, Kinoyama I, Matsuhisa A, Kudou M and Sasamata M: Broad spectrum and potent antitumor activities of YM155, a novel small-molecule survivin suppressant, in a wide variety of human cancer cell lines and xenograft models. Cancer Sci 102: 614-621, 2011.

92. Yan X and Su H: YM155 Down-regulates survivin and induces P53 Up-regulated modulator of apoptosis (PUMA)-dependent in oral squamous cell carcinoma cells. Med Sci Monit 23: 1963-1972, 2017.

93. Zhang L, Zhang W, Wang YF, Liu B, Zhang WF, Zhao YF, Kulkarni AB and Sun ZJ: Dual induction of apoptotic and autophagic cell death by targeting survivin in head neck squamous cell carcinoma. Cell Death Dis 6: e1771, 2015.

94. Tolcher AW, Mita A, Lewis LD, Garrett CR, Till E, Daud AI, Patnaik A, Papadopoulos K, Takimoto C, Bartels P, et al: Phase I and pharmacokinetic study of YM155, a small-molecule inhibitor of survivin. J Clin Oncol 26: 5198-5203, 2008.

95. Satoh T, Okamoto I, Miyazaki M, Morinaga R, Tsuya A, Hasegawa Y, Terashima M, Ueda S, Fukuoka M, Ariyoshi Y, et al: Phase I study of YM155, a novel survivin suppressant, in patients with advanced solid tumors. Clin Cancer Res 15: 3872-3880, 2009. 
96. Giaccone G, Zatloukal P, Roubec J, Floor K, Musil J, Kuta M, van Klaveren RJ, Chaudhary S, Gunther A and Shamsili S: Multicenter phase II trial of YM155, a small-molecule suppressor of survivin, in patients with advanced, refractory, non-small-cell lung cancer. J Clin Oncol 27: 4481-4486, 2009.

97. Kelly RJ, Thomas A, Rajan A, Chun G, Lopez-Chavez A, Szabo E, Spencer S, Carter CA, Guha U, Khozin S, et al: A phase I/II study of sepantronium bromide (YM155, survivin suppressor) with paclitaxel and carboplatin in patients with advanced non-small-cell lung cancer. Ann Oncol 24: 2601-2606, 2013

98.Gurpinar E, Grizzle WE and Piazza GA: NSAIDs inhibit tumorigenesis, but how? Clin Cancer Res 20: 1104-1113, 2014.

99. Tinsley HN, Grizzle WE, Abadi A, Keeton A, Zhu B, Xi Y and Piazza GA: New NSAID targets and derivatives for colorectal cancer chemoprevention. Recent Results Cancer Res 191: 105-120, 2013.

100. Sato A, Mizobuchi Y, Nakajima K, Shono K, Fujihara T, Kageji T, Kitazato K, Matsuzaki K, Mure H, Kuwayama K, et al: Blocking COX-2 induces apoptosis and inhibits cell proliferation via the Akt/survivin- and Akt/ID3 pathway in low-grade-glioma. J Neurooncol 132: 231-238, 2017.

101. Scheper MA, Nikitakis NG, Chaisuparat R, Montaner S and Sauk JJ: Sulindac induces apoptosis and inhibits tumor growth in vivo in head and neck squamous cell carcinoma. Neoplasia 9: 192-199, 2007.

102. Chiou SK and Mandayam S: NSAIDs enhance proteasomic degradation of survivin, a mechanism of gastric epithelial cell injury and apoptosis. Biochem Pharmacol 74: 1485-1495, 2007.

103. Chiou SK, Hoa N, Hodges A, Ge L and Jadus MR: Indomethacin promotes apoptosis in gastric cancer cells through concomitant degradation of Survivin and Aurora B kinase proteins. Apoptosis 19: 1378-1388, 2014.

104. Olie RA, Simões-Wüst AP, Baumann B, Leech SH, Fabbro D, Stahel RA and Zangemeister-Wittke U: A novel antisense oligonucleotide targeting survivin expression induces apoptosis and sensitizes lung cancer cells to chemotherapy. Cancer Res 60: 2805-2809, 2000.

105. Talbot DC, Ranson M, Davies J, Lahn M, Callies S, André V, Kadam S, Burgess M, Slapak C, Olsen AL, et al: Tumor survivin is downregulated by the antisense oligonucleotide LY2181308: A proof-of-concept, first-in-human dose study. Clin Cancer Res 16: 6150-6158, 2010.

106. Hansen JB, Fisker N, Westergaard M, Kjaerulff LS, Hansen HF, Thrue CA, Rosenbohm C, Wissenbach M, Orum $\mathrm{H}$ and Koch T: SPC3042: A proapoptotic survivin inhibitor. Mol Cancer Ther 7: 2736-2745, 2008.

107. Sapra P, Wang M, Bandaru R, Zhao H, Greenberger LM and Horak ID: Down-modulation of survivin expression and inhibition of tumor growth in vivo by EZN-3042, a locked nucleic acid antisense oligonucleotide. Nucleosides Nucleotides Nucleic Acids 29: 97-112, 2010

108. Carrasco RA, Stamm NB, Marcusson E, Sandusky G, Iversen P and Patel BK: Antisense inhibition of survivin expression as a cancer therapeutic. Mol Cancer Ther 10: 221-232, 2011.
109. Kojima H, Iida M, Yaguchi Y, Suzuki R, Hayashi N, Moriyama H and Manome Y: Enhancement of Cisplatin sensitivity in squamous cell carcinoma of the head and neck transfected with a survivin antisense gene. Arch Otolaryngol Head Neck Surg 132: 682-685, 2006.

110. Tanioka M, Nokihara H, Yamamoto N, Yamada Y, Yamada K, Goto Y, Fujimoto T, Sekiguchi R and Uenaka K: Phase I study of LY2181308, an antisense oligonucleotide against survivin, in patients with advanced solid tumors. Cancer Chemother Pharmacol 68: 505-511, 2011.

111. Schmidt SM, Schag K, Müller MR, Weck MM, Appel S, Kanz L, Grünebach F and Brossart P: Survivin is a shared tumor-associated antigen expressed in a broad variety of malignancies and recognized by specific cytotoxic T cells. Blood 102: 571-576, 2003.

112. Schmitz M, Diestelkoetter P, Weigle B, Schmachtenberg F, Stevanovic S, Ockert D, Rammensee HG and Rieber EP: Generation of survivin-specific CD8+ T effector cells by dendritic cells pulsed with protein or selected peptides. Cancer Res 60: 4845-4849, 2000.

113. Miyazaki A, Kobayashi J, Torigoe T, Hirohashi Y, Yamamoto T, Yamaguchi A, Asanuma H, Takahashi A, Michifuri Y, Nakamori K, et al: Phase I clinical trial of survivin-derived peptide vaccine therapy for patients with advanced or recurrent oral cancer. Cancer Sci 102: 324-329, 2011

114. Hirohashi Y, Torigoe T, Maeda A, Nabeta Y, Kamiguchi K, Sato T, Yoda J, Ikeda H, Hirata K, Yamanaka N and Sato N: An HLA-A24-restricted cytotoxic T lymphocyte epitope of a tumor-associated protein, survivin. Clin Cancer Res 8: $1731-1739,2002$

115. Idenoue S, Hirohashi Y, Torigoe T, Sato Y, Tamura Y, Hariu H, Yamamoto M, Kurotaki T, Tsuruma T, Asanuma H, et al: A potent immunogenic general cancer vaccine that targets survivin, an inhibitor of apoptosis proteins. Clin Cancer Res 11: 1474-1482, 2005.

116. Liu Z, Wang T, Zhang Z, Tang S, Feng S, Yue M, Hu M, Xuan L and Chen Y: Survivin downregulation using siRNA nanoliposomes inhibits cell proliferation and promotes the apoptosis of MHCC-97H hepatic cancer cells: An in vitro and in vivo study. Oncol Lett 13: 2723-2730, 2017.

117. Zhang Z, Wang T, Liu Z, Tang S, Yue M, Feng S, Hu M, Xuan L and Chen Y: Small interfering RNA targeting of the survivin gene inhibits human tumor cell growth in vitro. Exp Ther Med 14: 35-42, 2017.

118. Li Y, Liu D, Zhou Y, Li Y, Xie J, Lee RJ, Cai Y and Teng L: Silencing of survivin expression leads to reduced proliferation and cell cycle arrest in cancer cells. J Cancer 6: 1187-1194, 2015.

119. Xu JH, Wang AX, Huang HZ, Wang JG, Pan CB and Zhang B: Survivin shRNA induces caspase-3-dependent apoptosis and enhances cisplatin sensitivity in squamous cell carcinoma of the tongue. Oncol Res 18: 377-385, 2010.

120. Chen XM, Luan XY, Lei DP, Ma XJ, Liu XX, Liu J and Pan XL: Suppression of survivin expression by short hairpin RNA induces apoptosis in human laryngeal carcinoma cells. ORL J Otorhinolaryngol Relat Spec 70: 168-175, 2008

121. Wang Y, Zhu H, Quan L, Zhou C, Bai J, Zhang G, Zhan Q and $\mathrm{Xu}$ N: Downregulation of survivin by RNAi inhibits the growth of esophageal carcinoma cells. Cancer Biol Ther 4: 974-978, 2005. 